\title{
Getting by with a Little Help from My Friends: Mental Rotation Ability after Tacit Peer Encouragement
}

\author{
Sheila Brownlow, Amanda J. Janas, Kathleen A. Blake, Kathleen T. Rebadow, \\ Lindsay M. Mellon \\ Department of Psychology, Catawba College, Salisbury, USA. \\ Email: sbrownlo@catawba.edu \\ Received March 12 ${ }^{\text {th }}, 2011$; revised April 15 $5^{\text {th }}, 2011$; accepted May 25, 2011.
}

\begin{abstract}
We examined how Mental Rotation (MR) ability was improved by presenting information that the task was one that could be accomplished. This information purportedly came from either peers or the experimenter. Men and women students completed 10 MR items from the Purdue Visualization of Rotations Test (Bodner \& Guay, 1997) and provided self-reports about their confidence in their abilities to perform rotations, background skills and experiences, and effort with the task. The peer-presentation technique improved performance on MR, as both men and women who read that other students had previously managed the tasks performed better than those who merely heard about the tasks, leaving an implied difficulty unaddressed or "in the air." When self-reported confidence in MR ability was held constant there were no gender differences in MR performance. The results suggest that appropriate peer models may improve performance on cognitive tasks, perhaps by increasing confidence in ability.
\end{abstract}

Keywords: Mental Rotation, Stereotype Threat, Gender Effects

\section{Introduction}

Success in high-status science and engineering fields may be due in part to facility with Mental Rotation (MR), a cognitive skill that involves the manipulation and transformation of three-dimensional objects in the head (Voyer, Voyer, \& Bryden, 1995). Research shows robust and consistent gender differences in MR, as men rotate three-dimensional objects faster and more accurately than women (Bodner \& Guay, 1997; Cherney \& Collaer, 2005; Resnick, 1993; Voyer et al., 1995; Walter, Roberts, \& Brownlow, 2000). Research also demonstrates that MR ability can be improved by select experiences that increase efficacy beliefs about MR

Hobbies, vocational pursuits, and leisure activities can help develop MR skills. Most of the activities that are crucial to rotation ability tend to be those that are traditionally in the domain of boys and men. For example, boys are more inclined to play with models and blocks (Newcombe, Bandura, \& Taylor, 1983; Voyer, Nolan, \& Nolan, 2000), and later are more likely to complement their play with academic choices in physical sciences and engineering that also involve using spatial skills (Bodner \& Guay, 1997). Thus, from childhood boys more than girls obtain practice and become more proficient with rotations, further affirming gender-related stereotypes about cognitive differences (Oswald \& Lindstedt, 2006). Early experience is important to MR, but not essential, as ability with spatial tasks can be facilitated for both men and women by training and practice (Baenninger \& Newcombe, 1989; Brownlow \& Miderski, 2002; Cherney, 2008; Voyer \& Isaacs, 1993). For women, especially, the benefit of training may depend on how closely the experience mimics actual MR tasks (Kass, Ahlers, \& Dugger, 1998; Roberts \& Bell, 2000; but not Baenninger \& Newcombe, 1989).
Beliefs about ability are key to understanding MR facility, particularly among women. For example, if an MR task is termed cognitive women will perform far better on the task than if it is described as a test of rotation (Sharps, Price, \& Williams, 1994). Because women understand that they are good at cognitive tasks they expect to perform well on them, but because they do not perceive themselves adept at MR they have a negative expectation about their performance, and their performance confirms that expectation. Taking away a salient time constraint may allow women to take their time, improving MR ability (Goldstein, Haldane, \& Mitchell, 1990; Scali, Brownlow, \& Hicks, 2000), and making explicit that women and men are equally capable will also improve performance (Wraga, Helt, Jacobs, \& Sullivan, 2006). Thus, expectations about ability and subsequent performance can be affected by external factors. However, performing under such conditions may result in a belief that performance is contingent on those external factors, resulting in a dispositional attribution to lack of ability and subsequently affecting beliefs about abilities as well as those about members of a peer reference group (Smith, 2006).

Knowledge that others question the abilities of members of your group may lead to stereotype threat (Steele, 1997), a condition created due to anxiety that others see members of your group as deficient in some ability. Stereotype threat can cause poor task performance due to concern that personal capability reflects the ability of an entire group (Steele \& Aronson, 1995). If you know the stereotype of your group, identify yourself as a member of that group, and are concerned about what you, your peers, or others in general will think about you (or your group), you may fail to perform up to your abilities (Shapiro, 2011; Shapiro \& Neuberg, 2007). For example, a White man could be concerned about his math skills in relation to those of his Asian friends. If he believes that his own math skills can and will be 
judged in contrast to those of Asian men, and if he is concerned that he is thus a representative of "his" peer group (in this case White men), then he may fail to perform to his level of capability (Aronson et al., 1999).

Both overt and implicit stereotype threats can hurt performance, regardless of whether the stereotype is accurate (Brown \& Josephs, 1999). The influence of stereotype threat is seen as a function of race or ethnicity (e.g., Aronson, Fried, \& Good, 2002; Gonzalez, Blanton, \& Williams, 2002; Shih, Pittinsky, \& Ambady, 1999; Steele \& Aronson, 1995), but can also be evoked in situations where there is concern about ability in any domain, including social sensitivity (Koenig \& Eagly, 2005), socioeconomic status (Croizet \& Claire, 1998), academic interest (Seibt \& Förster, 2004), spatial relations (Brownlow, Valentine, \& Owusu, 2008), and athleticism (Stone, Lynch, Sjomeling, \& Darley, 1999. The influence of stereotype threat emerges as soon as children understand stereotypes of how people of "their" group are expected to behave (Ambady, Shih, Kim, \& Pittinsky, 2001).

An example of how stereotype threat negatively influences cognitive performance concerns women and mathematics. Despite that there is clear evidence that the mathematical ability of women and girls is equal to that of men and boys (Else-Quest, Hyde, \& Linn, 2010), the stereotype of female deficiency in math relative to males persists. Such beliefs have predictable consequences in stereotype threat situations. For example, women will underperform on math tests when their math abilities are questioned (Cadinu, Maass, Frigerio, Impagliazzo, \& Latinotti, 2003; Carr \& Steele, 2009; Davies, Spencer, Quinn, \& Gerhardstein, 2002; Schmader, 2002; Spencer, Steele, \& Quinn, 1999). On the other hand, women will perform well when they are told that a test is being used to gather baseline data rather than to evaluate performance (Gonzalez et al., 2002), when presented with a high-achieving role model (Lesko \& Corpus, 2006; Marx \& Roman, 2002), if potential differences are negated explicitly (Smith \& White, 2002), when their abilities as good students and research participants are noted (McIntyre, Paulson, Lord, 2003), or when another of their group member categories - one which is not deficient in math-is made more accessible (Gresky, Ten Eyck, Lord, \& McIntyre, 2005).

Several challenges to good task performance are likely under stereotype threat. For example, people working under stereotype threat face increased arousal (O'Brien \& Crandall, 2003), concern of performance evaluation (Spencer et al., 1999), and general nervousness (Brodish \& Devine, 2009). Arousal in turn leads to difficulties in concentration, thereby decreasing working memory and creating a burdensome cognitive load to an already-demanding situation (Schmader, Johns, \& Forbes, 2008; Wraga et al., 2006). These encumbrances do not go unnoticed, as people who fear confirming a negative belief about their group exert more effort (Aronson et al., 1999), worry that they may be making mistakes (Brodish \& Devine, 2009), and become overly focused on the task (Keller \& Dauenheimer, 2003). In sum, working under conditions of stereotype threat makes a difficult situation more difficult, and may lead to a hypersensitivity to performance.

The influence of stereotype threat on performance in any given area extends beyond the task at hand, creating doubt about ability in the future (Schmader, Johns, \& Barquissau,
2004) and ultimately leading to a lack of interest in that area (Aronson et al., 2002; Keller \& Dauenheimer, 2003). For example, a lack of efficacy ("it's not my thing") along with disengagement ("and I'm not interested, anyhow") together may work in tandem to dissuade women from entering fields, taking courses, and engaging in endeavors that require certain cognitive abilities such as math, and perhaps MR as well.

Our research examined whether a stereotype threat could be nullified by presenting examples of gender-specific successes directly from either peers or from the experimenter, focusing on how people (women or men) have shown ability on an MR task. Nullification has been used to alleviate the negative effects of stereotype threats concerning women's math abilities. Such nullification affords women an opportunity to perform better, and thus we expected that women who performed MR under a nullified stereotype threat would perform better than those who worked with a threat "in the air." Moreover, we predicted that men's performances would be less negatively affected by the nullification procedure, as they would not experience stereotype threat for MR. We also examined the influence of several self-perception and background experience variables to MR, which we expected might be related to MR ability for both men and women.

\section{Method}

\section{Participants and Design}

A total of 96 students (48 women, 48 men) volunteered or received partial credit to participate. ${ }^{1}$ Each man and woman was assigned randomly into one of three groups created by manipulating information about the tasks, effected by providing purported information from same-gender peers asserting that the tasks could be accomplished (termed "peer nullification"), by giving parallel information from the experimenter ("experimenter nullification"), or by omitting background about the tasks and leaving a stereotype threat for women "in the air." The manipulations produced a $2 \times 3$ (Participant Gender $\times$ Nullification Condition: Peer, Experimenter, None) design.

\section{Dependent Measures}

Mental rotation. Participants completed 10 items from the Purdue Visualization of Rotations Test (PVRT; Bodner \& Guay, 1997). The test requires an examination of a sample three-dimensional shape that is paired with an identical shape that has been rotated along two orientations (e.g., right and down). Below the sample shape is a test shape along with five different possible rotated options of the test shape; only one depicts the correct rotation paralleling the changes seen in the sample. Raw score (correct responses), adjusted score (correct responses minus incorrect responses) to accommodate guessing (see Goldstein et al., 1990), and time-on-task were recorded.

Self-efficacy, self-handicapping, and perceptions of stereotype threat. As noted previously, there are several mediators of performance under stereotype threat, including evaluation apprehension (Spencer et al., 1999), self-handicapping (Stone, 2002), nervousness (Schmader, 2002), effort (Cadinu et al., 2003), confidence (Smith, 2006), perceived pressure and difficulty (Aronson et al., 1999), self-evaluation (Keller, 2002), cognitive load (Schmader et al., 2008), and stereotype en- 
dorsement (Schmader et al., 2004). Thus, participants reported their perceptions about the tasks, their performance, and their abilities along several 7-point bipolar scales, each with opposite meaning endpoints (such as 1 not at all frustrated to 7 very frustrated). Each measure used was adapted from previous research, as noted above. Included were pressure to work quickly, success with the tasks, enjoyment, pressure to be accurate, amount of frustration experienced, "trickiness" of the tasks, ability with problem-solving (MR and with similar tasks), effort, motivation, task difficulty, amount of recent life stress, evaluation apprehension, nervousness during the experiment, fear of "looking bad," belief about whether gender influences ability with MR, similarity of problems to tasks used daily, and concern about whether performance might reflect on judgments about their gender.

Background experiences. Certain academic experiences and engagement in sports and various leisure activities provide practice with MR (Brownlow, McPheron, \& Acks, 2003; Voyer \& Isaacs, 1993). Participants therefore provided a self-report about their abilities in four areas: sports, science, math, and graphic design/art. Each self-perception was assessed on a 7-point scale (endpoints labeled 1 not good at all to 7 very good). Students also indicated how much dance/choreography experience they had, whether they had taken college chemistry courses, for how long they had played collegiate and/or high school sports, and the number of hours per week they played interactive video/Internet games (from choices of 0-2, 3-6, 7-10, 11-14, 15+). Nullification Condition: Peer, Experimenter, None) design.

\section{Procedure}

Participants entered a sound-attenuated cubicle, provided consent to engage in an experiment on "laboratory tasks," and were then given experiment directions, which were also read to them by a woman experimenter. In two conditions the directions contained the nullification manipulation. All participants read, and heard, "you are about to complete several problem solving tasks which involve rotating multi-dimensional blocks. I'll describe the example for you before you begin, so I can answer any questions you have."

The students in the control group received no other information, because the foregoing instructions alone would cause stereotype threat for women. Students in the peer-nullification condition then read and heard:

"These types of block rotations tasks have been used here in many problem-solving studies and normally women [men] students have had really positive responses. Recent women [men] participants from last fall have said: 'Challenging, but fun...,' 'if you concentrate and try it can be done well,' 'these use the abilities that I use in everyday life..., and ...nonstressful...",

Students in the experimenter-nullified group heard the experimenter explain:

"These types of block rotation tasks have been used here in a lot of studies of how women [men] do problem solving. I think that you will find that if you concentrate and try you will do well, especially if you tie the tasks to other problem-solving you do in your everyday life. You will find them challenging, but fun, and not stressful".

After these directions and the presentation of a sample item, participants were left alone in the cubicle, and instructed to ring a bell to signal when they started and finished the rotations. The time taken was recorded, and the participants were then given a booklet including the efficacy questions, presented in one of two counterbalanced orders across conditions, followed by the questions about background experiences. After participants completed their questions they were allowed to ask questions and leave; full debriefing took place at a later date.

\section{Results}

\section{Mental Rotation Performances According to Gender and Nullification Condition}

To examine how gender and type of nullification information (from experimenter or peers) influenced MR, raw score, adjusted score, and time to complete the rotations were separately entered in $2 \times 3$ (Participant Gender $\times$ Nullification Condition: Peer, Experimenter, None) ANOVAs. The means and standard deviations from these analyses can be seen in Table 1.

For raw score, there were main effects of nullification condition, $F(2,90)=3.15, M S E=6.12, p=.05$, partial $\eta^{2}=.07$, and gender, $F(1,90)=5.46, p=.022$, partial $\eta^{2}=.06$. Men $(M=$ $6.33, S D=2.54)$ outperformed women $(M=5.15, S D=2.51)$, and a Scheffé test revealed that those students who received purported information from their peers about whether the tasks could be accomplished $(M=6.53, S D=2.26)$ outperformed those who heard no nullification information $(M=4.97, S D=$ $2.86), p<.05$. Students in the experimenter nullification condition $(M=5.72, S D=2.43)$ performed at a rate not significantly

Table 1.

Means and SDS for MR performance measures as a function of nullification procedure.

\begin{tabular}{ccccc}
\hline \multicolumn{5}{c}{ Stereotype Threat Nullification Condition } \\
\hline & None & Experimenter & Peer & Total \\
\hline Raw Score & 5.69 & 6.13 & 7.19 & $6.33_{\mathrm{c}}$ \\
Men & $(3.11)$ & $(3.11)$ & $(1.97)$ & $(2.54)$ \\
Raw Score & 4.25 & 5.31 & 5.88 & $5.15_{\mathrm{d}}$ \\
Women & $(2.46)$ & $(2.55)$ & $(2.39)$ & $(2.51)$ \\
& & 5.72 & $6.53_{\mathrm{b}}$ & \\
Raw Score & $4.97 \mathrm{a}$ & $(2.43)$ & $(2.26)$ & \\
Total & $(2.86)$ & 2.25 & 4.25 & $2.73_{\mathrm{c}}$ \\
Adjusted & 1.69 & $(4.61)$ & $(3.92)$ & $(4.93)$ \\
Men & $(5.98)$ & 0.63 & 1.58 & $0.31 \mathrm{~d}$ \\
Adjusted & -1.19 & $(5.10)$ & $(4.76)$ & $(4.95)$ \\
Women & $(4.92)$ & 1.44 & 2.88 & \\
& & $(4.85)$ & $(4.51)$ & \\
Adjusted & 0.25 & & 290.56 & 317.08 \\
Total & $(5.58)$ & $(201.79)$ & $(137.56)$ & $(153.37)$ \\
Time in s & 297.13 & 363.56 & 310.44 & 317.90 \\
Men & $(102.87)$ & & & \\
Time in s & 305.00 & 338.25 & $(117.44)$ & $(113.43)$ \\
Women & $(118.45)$ & $(108.70)$ & 300.50 & \\
Time in s & 301.96 & 350.91 & $(126.22)$ & \\
Total & $(109.20)$ & $(159.96)$ & \\
\hline
\end{tabular}

Note: raw score varies from 0 to 10 ; adjusted scores from -20 to 20 . Means with different subscripts within rows, and those with different subscripts in the total column, are significantly different, $p<.05$. 
different from those in the control or the peer-nullification group. The Gender $\times$ Nullification interaction was not significant, $F(2,90)<1$, ns.

Results for adjusted scores paralleled those just reported for gender in that men $(M=2.73, S D=4.93)$ performed better than women $(M=0.31, S D=4.95), F(1,90)=5.79, M S E=24.12, p$ $<.02$, partial $\eta^{2}=.06$. However, the main effect of nullification condition for the adjusted scores was not significant, $F(2,90)=$ $2.29, p=.11$, nor was the interaction, $F(2,90)<1$, ns. There were no significant effects of gender or nullification condition for time to complete the task, $F \mathrm{~s}(1,90)<1$, ns, and $F(2,90)=$ $1.46, p=.24$. There was also no interaction between gender and nullification condition for time, $F(2,90)<1$, ns. Thus, performance (raw score and an adjusted score for guessing) was higher for men, but also in the case of raw score by type of directions given to students.

\section{Influence on Self-Reports of Performance and Background on MR Performance}

Because we measured several possible mediators of performance, data reduction was necessary to combine similar constructs. Self-reports of perceptions of the task and performance were subjected to a principle components factor analysis with varimax rotation. This analysis accounted for $57 \%$ of the variance and produced five factors; each factor and its loading is shown in Table 2. We termed the first factor Confidence, because it included belief that personal performance was good (.86), enjoyment of MR tasks (.82), ability with MR (.81), task difficulty (.77), motivation to do well (.63), and lack of frustration (-.59). The second factor was named Pressure, and in-

Table 2.

Results of factor analysis on self-reports of performance, efficacy, and enjoyment.

\begin{tabular}{lcc}
\hline \multicolumn{1}{c}{ Factor } & Variance & Measure/Loading \\
\hline Confidence & $(24 \%)$ & Belief that performance was good (.86) \\
& & Ability with MR (.81) \\
& & Task Difficulty (.77) \\
& & Motivation to do well (.63) \\
Pressure & & Frustration (-.59) \\
& & Pressure to do well (.79) \\
& & Worry about performance (.75) \\
Test Type & & Pressure to be quick (.67) \\
& & Belief that women perform well (.57) \\
Effort & & Degree that test uses daily skills (.52) \\
No Stereotype Threat & $(5 \%)$ & Fear of confirming stereotype (-.59)
\end{tabular}

Note: based on $N=96$. cluded fear of looking bad (.81), pressure to do well (.79), concern about performance (.75), and pressure to be quick (.67). The third factor was Test Type, which encompassed agreement that women perform well on the test (.57), and degree to which the tasks call on daily skills (.52). Effort was the fourth factor, comprised solely of effort expended (.65). Finally, the fifth factor was named No Stereotype Threat, and included lack of fear to confirm a stereotype about the participant's own group membership (-.59).

A second principle components analysis with varimax rotation was calculated on the measures of background and MR experience. The analysis accounted for a total variance of $64 \%$; the four resultant factors and their loadings can be seen in Table 3. The first factor was coined Sports Experience, and included self-reports of athletic ability (.85), years playing collegiate sports (.82), and years playing high school sports (.78). The second factor was named Science Background, and encompassed self-judgments of science ability (.79) and number of chemistry courses taken (.56). Self-reported ability in graphic arts (.71), and hours playing video games per week (.51) comprised the third factor named Video/Graphic Arts Background. The fourth factor was labeled Math Ability and included only self-reported ability in math (.89).

\section{Relationship between Performance and Self-Reports of Efficacy and Background}

Factor means, after reverse scoring as needed, were calculated. These means were then correlated with the performance measures (MR time, raw score, and adjusted score). The relationships among self-reported efficacy/enjoyment factors, academic and sports background, and performance can be seen in Table 4. To summarize, self-reported confidence was the only variable positively related to raw score, $r(94)=.49, p<.001$; no other correlations with raw score were significant, all $r \mathrm{~s}(94)$ $=-12$ to $.18, n s^{2}{ }^{2}$ Self-reported confidence was also positively related to adjusted score, $r(94)=.52, p<.001$, as was self-reported video/graphic arts engagement, $r(94)=.21, p$ $=.043$. No other correlations were significant, all $r \mathrm{~s}(94)=-.12$ to .20 , all $n s$. Pressure and effort were both positively related to the time it took to complete the MR task, $r(94)=.27, p=.007$ and $r(94)=.23, p=.021$, but no other correlations were sig-

Table 3.

Results of factor analysis on self-reports of background and experience.

\begin{tabular}{lcc}
\hline Factor & Variance & Measure/Loading \\
\hline Sports Experience & $(22 \%)$ & Self-reported athletic ability (.85) \\
& & Years playing collegiate sports (.82) \\
& & Years playing high school sports (.78) \\
Science Background & $(16 \%)$ & Self-reported science ability (.79) \\
& & Number of chemistry courses (.56) \\
Video/Graphic Arts & $(14 \%)$ & Self-reported ability/graphic arts (.71) \\
Background & & Hours playing video games/week (.51) \\
Math Ability & $(12 \%)$ & Self-reported math ability \\
\hline
\end{tabular}

Note: $N=96$. 
Table 4.

Correlations between self-reported efficacy, background factors, and MR performance.

\begin{tabular}{cccc}
\hline \multirow{2}{*}{ Factor } & \multicolumn{3}{c}{ MR Performance } \\
\cline { 2 - 4 } & Raw & Adjusted & Time \\
\hline Pressure to & & & \\
Perform Well & -.12 & -.11 & $.27^{* *}$ \\
Effort & .03 & .05 & $.23^{* *}$ \\
Confidence & $.49^{* * *}$ & $.52^{* * *}$ & .00 \\
Stereotype & & & \\
Threat & -.03 & -.04 & -.13 \\
Test Type & -.07 & .12 & -.12 \\
Sports Background & .00 & .02 & -.04 \\
Science Background & .10 & .10 & -.01 \\
Video/Graphic Arts & .18 & $.21^{*}$ & -.04 \\
Engagement & & & .09 \\
Math Ability & .18 & .20 & \\
\hline
\end{tabular}

Note: $D f=94 .{ }^{*} p<.05,{ }^{* *} p<.01, * * * p<.001$.

nificant with this measure, $r \mathrm{~s}(94)=-.13$ to .09 .

\section{Influence of Self-Reports of Efficacy and Background as Mediators of Gender and Nullification Effects on MR Performance}

Because self-reported confidence was positively related to raw score and adjusted score, and time was positively related to pressure to perform and effort exerted, these factors were employed as covariates in three separate $2 \times 3$ (Gender $\times$ Nullification Technique) ANCOVAs, paralleling those previously reported. The analyses with raw and adjusted scores used confidence as the covariate, and the analysis for time used both pressure and effort.

Confidence was a significant covariate in the analysis with raw score, $F(1,89)=24.54, M S E=4.91, p<.001$, partial $\eta^{2}$ $=.22$; when added into the ANCOVA, the main effect of gender was no longer significant, $F(1,89)=1.30, p=.26$. Nullification technique remained significant, just as it was without the covariate, $F(2,89)=3.72, p=.028$, partial $\eta^{2}=.08$. There was no interaction between gender and nullification condition, $F(2$, $89)<1$, ns. Similarly, confidence was significant to adjusted score, $F(1,89)=28.71, M S E=18.50, p<.001$, partial $\eta^{2}=.24$, and when held constant, the gender influence on adjusted score was no longer significant, $F(1,89)=1.33, p=.25$. The effect of nullification condition became marginally significant, $F(2,89)$ $=2.77, p=.068$. (Means are seen in Table 1.) There was no significant interaction between gender and nullification condition, $F(2,89)<1$, ns.

Self-perceived pressure was a significant covariate in the time analysis, $F(1,89)=10.96, M S E=15279.75, p=.001$, partial $\eta^{2}=.08$, but effort was not, $F(1,89)=2.71, p=.10$. The ANCOVA did not alter substantially the findings concerning the lack of influence of gender and nullification technique, all $F \mathrm{~s}(1,89)$ and $(2,89)<1$, ns. In sum, holding constant confidence ameliorated the gender differenced in MR (measured through both raw and adjusted scores), but not the effect of the source of stereotype threat nullification. Students who read peer reports about how the tasks could be done performed better than those for whom the stereotype threat remained inherent in the situation.

\section{Discussion}

Our findings demonstrate two key pieces to understanding MR performance under stereotype threat. First, having peers provide information to suggest that success on a task could be achieved was an effective way of providing a boost in performance on MR tasks for both women and men when compared to providing no information about others' behavior. The same information purportedly from an experimenter did not result in a significant increase in MR accuracy. The influence of peer models to increase MR ability remained even after confidence was held constant. Paralleling the findings concerning the impact of stereotype threat nullification on women's mathematics performance, our data suggest that stereotype threat was nullified during work on MR by the presentation of a positive example (Lesko \& Corpus, 2006; McIntyre et al., 2002). However, we found that only a peer (rather than, for example, a competent experimenter) was effective to increase performance for women.

A second important finding focuses on confidence, or performance expectancy, for women working under conditions of stereotype threat. When confidence was held constant the gender difference in MR favoring men was no longer significant. Confidence was a function of task enjoyment, MR ability, lack of frustration, belief that performance was good, framing the task as a difficult challenge, and motivation to perform. Thus, confidence may have been a function of a post-hoc (and accurate) estimation of how well participants performed. That confidence was linked to performance confirms that MR, like other cognitive abilities, can be shaped by behavior as well as by a situational factor as subtle as knowledge that people of the same age, gender, and status in life are capable of certain tasks. Because situation-specific negative stereotypes lower self-confidence in ability (Cadinu et al., 2003; Steele, 1997), techniques to increase confidence are essential to increasing performance for all people, but particularly for women whose low performance expectations may lead, ultimately, to a tendency to avoid the task at hand (Smith, 2006).

Our results also demonstrate a "boost" in MR ability when encouragement was given (cf. Davies et al., 2002; Keller, 2002), but less proficiency when a threat was left unaddressed, yet present (Brown \& Josephs, 1999; Sekaquaptewa \& Thompson, 2003; Schmader, 2002). Group members under stereotype threat who are informed in a subtle manner that people like them are capable show increases in cognitive performance (Ambady et al., 2001; Cheryan \& Bodenhausen, 2000; Shih, Ambady, Richeson, Fujita, \& Gray, 2002), a finding which helps explain why women benefited from this information. On the other hand, members of a non-stereotyped group (in this case, men) can have their performances "boosted" under an overt, rather than subtle, challenge (Davies et al., 2002; Shih et 
al., 2002). Because men were not working under stereotype threat, however, they may simply have been responding in a positive way to the presentation of information that the task had been accomplished by others like them.

Whether the manipulation was noticed in the same way by men and women cannot be discerned from the MR findings. We provided four sample student quotes to research participants, each of which was a two-10 word phrase, buried within the larger context of experiment directions. Absent a retrospective manipulation check asking whether these phrases were recalled, an understanding of whether this manipulation was subtle is not possible here; therefore in future work an assessment of students' recall of directions is necessary. Additionally, students may have responded to two possible group membership clues during the directions: their gender and their status as research participants. Highlighting membership of a group of good performers (peers from a participant pool), rather than focusing on gender, may have created for women a situation where performance was improved (McIntyre et al., 2003; Shih et al., 1999). Learning the same information from the experimenter was not sufficient to improve performance. Or, women may have seen previous (women) research participants who liked the experiment as role models (Lesko \& Corpus, 2006; Marx \& Roman, 2002). Although men were not working under a stereotype threat, they may have bettered their performance simply because they were rising to a challenge, already confident in their cognitive abilities.

One other key to understanding how and men and women responded differently under the manipulations focuses on the type of stereotype threat each may have experienced. According to Shapiro (2011; Shapiro \& Neuberg, 2007), stereotype threat is not a singular phenomenon, as there are three possible sources of threat-yourself, your peers, or outsiders. The feared outcome of the threat could focus on any of those thinking badly about you as a member of the group you represented. Consequently, even people who are not strongly identified with the domain in question could be prey to one of those forms of threat. They would merely need to believe that someone (such as an experimenter) would have access to information about performance and believe those people value the performance quality on the task at hand. Therefore, strong identification and concern about the domain may not be a necessary condition because of the worry that others will be evaluating you or members of your group based on your performance.

Several background influences shown to affect MR performances were not crucial to MR ability in this study. Unlike findings in other studies that have employed the PVRT (see Bodner \& Guay, 1997; Brownlow et al., 2003), science background did not show a positive relationship with MR ability ${ }^{3}$. However, the students in this study were primarily in their first and second year of college and few $(n=20)$ had science background. Background in sports was also not important to MR, although other studies have shown that, particularly for men, motor performances require rotation and athletes may be thus better adept at MR (Balentine \& Brownlow, 2006; Voyer \& Isaacs, 1993). Other factors that have been shown to affect problem-solving performance, such as self-handicapping, pressure, undue cognitive load, and stereotype endorsement, were not related to MR. Confidence may have been so important to performance (or it may have reflected, in retrospect, a good performance) that these other variables were less important, either because they didn't impinge on performance or because the retrospective self-report used did not locate such factors. Women did not take more time with the tasks than did men despite that there were no time limits; students who took a long time did, however, report trying hard and experiencing performance pressure.

In sum, MR skill can be improved in both men and women through information that others like them have been successful on a cognitive task. For women, this information nullified a stereotype threat, allowing them to perform better than when a threat remained available and not discounted. Men also performed well with the same peer-related information, in all likelihood due to simple knowledge that others had accomplished the task. More importantly, gender differences in MR were related to confidence about task performance. Thus, appropriate peer models may provide others with an understanding that they are capable, and in turn increase the likelihood that they will succeed.

\section{References}

Ambady, N., Shih, M., Kim, A., \& Pittinsky, T. L. (2001). Stereotype susceptibility in children: Effects of identity activation on quantitative performance. Psychological Science, 12, 385-390. doi:10.1111/1467-9280.00371

Aronson, J., Fried, D. B., \& Good, C. (2002). Reducing the effects of stereotype threat on African American college students by shaping theories of intelligence. Journal of Experimental Social Psychology, 38, 113-125. doi:10.1006/jesp.2001.1491

Aronson, J., Lustina, M. J., Good, C., Keough, K., Steele, C. M., \& Brown, J. (1999). When white men can't do math: Necessary and sufficient factors in stereotype threat. Journal of Experimental Social Psychology, 35, 29-46. doi:10.1006/jesp.1998.1371

Baenninger, M., \& Newcombe, N. (1989). The role of experience in spatial test performance: A meta-analysis. Sex Roles, 20, 327-344. doi:10.1007/BF00287729

Balentine, C. B., \& Brownlow, S. (2006). Does making salient task relevance to group affiliation decrease the performance of men athletes on spatial tasks? Psi Chi Journal, 11, 37-44.

Bodner, G. M., \& Guay, R. B. (1997). The purdue visualization of rotations test. The Chemical Educator, 2, 118. doi:10.1007/s00897970138a

Brodish, A. B., \& Devine, P. G. (2009). The role of performance-avoidance goals and worry in mediating the relationship between stereotype threat and performance. Journal of Experimental Social Psychology, 45, 180-185. doi:10.1016/j/jesp.2008.08.005

Brown, R. P., \& Josephs, R. A. (1999). A burden of proof: Stereotype relevance and gender differences in math performance. Journal of Personality and Social Psychology, 76, 246-257. doi: 10.1037/0022-3514.76.2.246

Brownlow, S., McPheron, T. K., \& Acks, C. N. (2003). Science background and spatial abilities in men and women. Journal of Science Education and Technology, 12, 371-380. doi:10.1023/B:JOST.0000006297.90536.7c

Brownlow, S., \& Miderski, C. A. (2002). How gender and college chemistry experience influence mental rotation abilities. Themes in Education, 3, 133-140.

Brownlow, S., Valentine, S. E., \& Owusu, A. (2008). Women athletes' mental rotation under stereotypic threat. Perceptual and Motor Skills, 107, 307-336. doi:10.2466/pms.107.1.307-316

Cadinu, M., Maass, A., Frigerio, S., Impagliazzo, L., \& Latinotti, S. (2003). Stereotype threat: The effect of expectancy on performance. European Journal of Psychology, 33, 267-285.

Carr, P. B., \& Steele, C. M. (2009). Stereotype threat and inflexible 
perseverance in problem solving. Journal of Experimental Social Psychology, 45, 853-859. doi:10.1016/j.jesp.2009.03.003

Cheryan, S., \& Bodenhausen, G. V. (2000). When positive stereotypes threaten intellectual performance: The psychological hazards of “model minority" status. Psychological Science, 11, 399-402. doi:10.1111/1467-9280.00277

Cherney, I. D. (2008). Mom, let me play more computer games: They improve my mental rotation skills. Sex Roles, 59, 776-786. doi:10.1007/s11199-008-9498-Z

Cherney, I. D., \& Collaer, M. L. (2005). Sex differences in line judgment: Relationship to mathematics preparation and strategy use. Perceptual and Motor Skills, 100, 615-627. doi:10.2466/PMS.100.3.615-627

Croizet, J.-C., \& Claire, T. (1998). Extending the concept of stereotype threat to social class: The intellectual underperformance of students from low socioeconomic backgrounds. Personality and Social Psychology Bulletin, 24, 588-594. doi:10.1177/0146167298246003

Davies, P. G., Spencer, S. J., Quinn, D. M., \& Gerhardstein, R. (2002). Consuming images: How television commercials that elicit stereotype threat can restrain women academically and professionally. Personality and Social Psychology Bulletin, 28, 1615-1628. doi:10.1177/014616702237644

Else-Quest, N. M., Hyde, J. S., \& Linn, M. C. (2010). Cross-national patterns of gender differences in mathematics: A meta-analysis. Psychological Bulletin, 136, 103-127.

doi: $10.1177 / 014616702237644$

Goldstein, D., Haldane, D., \& Mitchell, C. (1990). Sex differences in visual-spatial ability: The role of performance factors. Memory and Cognition, 18, 546-550. doi:10.3758/BF03198487

Gonzalez, P. M., Blanton, H., \& Williams, K. J. (2002). The effects of stereotype threat and double minority status on the test performance of Latino women. Personality and Social Psychology Bulletin, 28, 656-670.

Gresky, D. M., Ten Eyck, L. L., Lord, C. G., \& McIntyre, R. B. (2005). Effects of salient multiple identities on women's performance under mathematics stereotype threat. Sex Roles, 53, 703-716. doi:10.1007/s11199-005-7735-2

Kass, S. J., Ahlers, R. H., \& Dugger, M. (1998). Eliminating gender differences through practice in an applied visual space task. Human Performance, 11, 337-349. doi:10.1207/s15327043hup1104_3

Keller, J. (2002). Blatant stereotype threat and women's math performance: Self-handicapping as a strategic means to cope with obtrusive negative performance expectations. Sex Roles, 47, 193-198. doi:10.1023/A:1021003307511

Keller, J., \& Dauenheimer, D. (2003). Stereotype threat in the classroom: Dejection mediates the disrupting threat effect on women's math performance. Personality and Social Psychology Bulletin, 29, 371-381. doi: $10.1177 / 0146167202250218$

Koenig, A. M., \& Eagly, A. H. (2005). Stereotype threat in men on a test of social sensitivity. Sex Roles, 52, 489-496. doi:10.1007/s11199-005-3714-x

Lesko, A. C., \& Corpus, J. H. (2006). Discounting the difficult: How high math-identified women respond to stereotype threat. Sex Roles, 54, 113-125. doi:10.1007/s11199-005-8873-2

Marx, D. M., \& Roman, J. S. (2002). Female role models: Protecting women's math test performance. Personality and Social Psychology Bulletin, 28, 1183-1193. doi:10.1177/01461672022812004

McIntyre, R. B., Paulson, R. M., \& Lord, C. G. (2003). Alleviating women's mathematic stereotype threat through salience of group achievements. Journal of Experimental Social Psychology, 39, 83-90. doi:10.1016/S0022-1031(02)00513-9

Newcombe, N., Bandura, M. M., \& Taylor, D. G. (1983). Sex differences in spatial ability and spatial activities. Sex Roles, 9, 377-385. doi:10.1007/BF00289672

O'Brien, L. T., \& Crandall, C. S. (2003). Stereotype threat and arousal: Effects on women's math performance. Personality and Social Psychology Bulletin, 29, 782-289.

Oswald, D. L., \& Lindstedt, K. (2006). The content and function of gender self-stereotypes: An exploratory investigation. Sex Roles, 54,
447-458. doi:10.1007/s11199-006-9026-y

Resnick, S. M. (1993). Sex differences in mental rotations: An effect of time limits? Brain and Cognition, 21, 71-79. doi:10.1006/brcg.1993.1005

Roberts, J. A., \& Bell, M. A. (2000). Sex differences on a computerized mental rotation task disappear with computer familiarization. Perceptual and Motor Skills, 91, 1027-1034. doi:10.2466/PMS.91.7.1027-1034

Scali, R. M., Brownlow, S., \& Hicks, J. L. (2000). Gender differences in spatial task performance as a function of speed or accuracy orientation. Sex Roles, 43, 359-376. doi:10.1023/A:1026699310308

Schmader, T. (2002). Gender identification moderates stereotype threat effects on women's math performance. Journal of Experimental Social Psychology, 38, 194-201. doi:10.1006/jesp.2001.1500

Schmader, T., Johns, M., \& Barquissau, M. (2004). The costs of accepting gender differences: The role of stereotype endorsement in women's experience in the math domain. Sex Roles, 50, 835-850. doi:10.1023/B:SERS.0000029101.74557.a0

Schmader, T., Johns, M., \& Forbes, C. (2008). An integrated process model of stereotype threat effects on performance. Psychological Review, 115, 336-356. doi:10.1037/0033-295X.115.2.336

Seibt, B. F., \& Förster, J. (2004). Stereotype threat and performance: How self-stereotypes influence processing by inducing regulatory foci. Journal of Personality and Social Psychology, 87, 38-56. doi:10.1037/0022-3514.87.1.38

Sekaquaptewa, D., \& Thompson, D. (2003). Solo status, stereotype threat, and performance expectancies: Their effects on women's performance. Journal of Experimental Social Psychology, 39, 68-74. doi:10.1016/S0022-1031(02)00508-5

Shapiro, J. R. (2011). Different groups, different threats: A mulit-threat approach to the experience of stereotype threats. Personality and Social Psychology Bulletin, 37, 464-480. doi:10:1177/0146167211398140

Shapiro, J. R., \& Neuberg, S. L. (2007). From stereotype threat to stereotype threats: Implications of a multi-threat framework for causes, moderators, mediators, consequences, and interventions. Personality and Social Psychology Review, 11, 107-130. doi: $10.1177 / 1088868306294790$

Sharps, M. J., Price, J. L., \& Williams, J. K. (1994). Spatial cognition and gender: Instructional and stimulus influences on mental image rotation performance. Psychology of Women Quarterly, 18, 413-425. doi:10.1111/j.1471-6402.1994.tb00464.x

Shih, M., Ambady, N., Richeson, A. J., Fujita, K., \& Gray, H. M. (2002). Stereotype performance boosts: The impact of self-relevance and the manner of stereotype activation. Journal of Personality and Social Psychology, 83, 638-647. doi:10.1037/0022-3514.83.3.638

Shih, M., Pittinsky, T. L., \& Ambady, N. (1999). Stereotype susceptibility: Identity salience and shifts in performance. Psychological Science, 10, 80-83. doi:10.1111/1467-9280.00111

Smith, J. L. (2006). The interplay among stereotypes, performance-avoidance goals, and women's math performance expectations. Sex Roles, 54, 287-296. doi:10.1007/s11199-006-9345-z

Smith, J. L., \& White, P. H. (2002). An examination of implicitly activated, explicitly activated, and nullified stereotypes on mathematical performance: It's not just a women's issue. Sex Roles, 47, 179-192. doi:10.1023/A:1021051223441

Spencer, S. J., Steele, C. M., \& Quinn, D. M. (1999). Stereotype threat and women's math performance. Journal of Experimental Social Psychology, 35, 4-28. doi:10.1006/jesp.1998.1373

Steele, C. M. (1997). A threat in the air: How stereotypes shape intellectual identity and performance. American Psychologist, 52, 613-629. doi:10.1037/0003-066X.52.6.613

Steele, C. M., \& Aronson, J. A. (1995). Stereotype threat and the intellectual test performance of African Americans. Journal of Personality and Social Psychology, 69, 797-811.

doi:10.1037/0022-3514.69.5.797

Stone, J. (2002). Battling doubt by avoiding practice: The effects of stereotype threat on self-handicapping in white athletes. Personality and Social Psychology Bulletin, 28, 1667-1678. 
doi: $10.1177 / 014616702237648$

Stone, J., Lynch, C. I., Sjomeling, M., \& Darley, J. M. (1999). Stereotype threat effects of Black and White athletic performance. Journal of Personality and Social Psychology, 77, 1213-1227. doi:10.1037/0022-3514.77.6.1213

Voyer, D., \& Isaacs, M. (1993, July). Sex differences in mental rotation: Role of practice and experience. Presented at the annual meeting of the Canadian Society for Brain, Behavior, and Cognitive Science, Toronto, Canada.

Voyer, D., Nolan, C., \& Voyer, S. (2000). The relation between everyday experience and spatial performance in men and women. Sex Roles, 43, 891-915. doi:10.1023/A:1011041006679

\section{Notes}

1) Participants were drawn from a pool located at a college with a predominantly Caucasian (84\%) population.

2) The correlation between the performance measures and confidence was significant for women alone, as well as for men alone. For men, confidence and MR (raw and adjusted, respectively) were $r \mathrm{~s}(46)=.50$ and $.53, p \mathrm{~s}<.001$; for women $r \mathrm{~s}(46)$
Voyer, D., Voyer, S., \& Bryden, M. P. (1995). Magnitude of sex differences in spatial abilities: A meta-analysis and consideration of critical variables. Psychological Bulletin, 117, 250-270. doi:10.1037/0033-2909.117.2.250

Walter, K. D., Roberts, A. E., \& Brownlow, S. (2000). Sex differences in mental rotation and other spatial abilities as measured through transcranial doppler sonography. Journal of Psychophysiology, 14, 37-45. doi:10.1027//0269-8803.14.1.37

Wraga, M., Helt, M., Jacobs, E., \& Sullivan, K. (2006). Neural basis of stereotype-induced shifts in women's mental rotation performance. Social Cognition and Affective Neuroscience, 2, 12-19. doi:10.1093/scan/ns1041

$=.41$ and $.45, p \mathrm{~s} \leq .004$.

3) For men, MR was positively related to the factor regarding math ability (self-reported) $r \mathrm{~s}(46)=.30$ (raw) and .33 (adjusted), both $p s<.041$. For women, MR scores (raw and adjusted) were positively related to the factor of science ability (self-reported ability and number of chemistry courses taken), both $r \mathrm{~s}(46)=.31, p \leq .035$. 